\title{
THE STUDY OF THE RHEOLOGICAL PROPERTIES OF PECTIN GELS WITH MONO- AND DISACCHARIDES
}

\author{
Antonella Dorohovich \\ Department of Technology of bakery and confectionery products \\ National University of food technologies \\ 68 Vladimirskaya str., Kiev, Ukraine, 01601 \\ Viktoriya Dorohovich \\ Department of Technology of bakery and confectionery products \\ National University of food technologies \\ 68 Vladimirskaya str., Kiev, Ukraine, 01601 \\ Julya Kambulova \\ Department of Technology of bakery and confectionery products \\ National University of food technologies \\ 68 Vladimirskaya str., Kiev, Ukraine, 01601 \\ kambulova.julya@yandex.ru
}

\begin{abstract}
At manufacturing of confectionary products can be used the different mono- and disaccharides - glucose, fructose, saccharose, lactulose and so on. The study of rheological parameters of pectin gels, made on the base of apple puree and different sugars, allowed establish the regularities of sugars influence on the state of pectin gels. It was revealed, that the effective viscosity of pectin gels, based on glucose and fructose, is higher than the one of pectin gel, based on saccharose that is explained by the formation of more number of hydrogenous connections between monosaccharides and pectin molecules. It was established, that the use of lactulose probiotics in composition of pectin gels, based on saccharose or glucose, increases the quantity of free moisture that decreases the effective viscosity of its structure. Or on the contrary, in pectin gels, based on fructose, the addition of lactulose decreases the total quantity of free moistrure that increases the effective viscosity of the structure. It can be explained by the more high solubility of lactulose comparing with saccharose and glucose and the lower one comparing with fructose. The received data ground technological modes of formation of gel-like confectionary masses, namely the increase of the temperature of formation of gels, based on fructose and glucose. At manufacturing of production with functional properties, the addition of lactulose, on the contrary, widens the temperature interval of masses formation, consequently, the formation temperature can be lowered.

At storage of gels at temperature $293 \mathrm{~K}$ their solidity increases. At the same time in gels, based on fructose, it is observed the crystals formation, connected with the low solubility of glucose. For prevention of crystals growth and attainment of the necessary structural-mechanical organoleptic parameters of gels, it is recommended to lower the glucose quantity by $30 \%$.

Keywords: pectin gels, gels, based on glucose, gels, based on fructose, probiotic lactuose, thixotropy, thixotropic properties, functional products, apple puree.

\section{Introduction}

Technologies of many confectionary products (fruit candy, fruit jelly, filling for caramel, cookies, muffins, biscuits, cakes, spice-cakes, and pies) are based on gelatinization of pectin substances of fruit puree [1-3]. Sugars are the important component of gelatinization mechanism. They serve not only for sweet taste but also for desolvation of pectin molecules, which results in their association with each other [4-6]. The receipts of confectionary products [7, 8] usually provide the use of saccharose disaccharide. But in the modern conditions the food products with fructose, glucose, lactulose and other sugars, presented on the raw material market, find their important place [9-14]. That is why the scientific interest also to the study of process of formation of pectin gels with the different mono- and disaccharides appears. The integral studies that allow present the analysis of rheological properties of pectin gels, based on apple puree with glucose, fructose, saccharose, lactulose would help at elaboration of scientifically grounded technologies of confectionary products. The studied pectin gels can be
\end{abstract}


used at manufacturing of child food products (with glucose), functional products (with lactulose) and deictic products for people with diabetes mellitus (with fructose).

\section{Materials and Methods}

The studies of influence of disaccharides (saccharose, lactulose) and monosacharides (glucose, fructose) on rheological properties of pectin gels were realized on the models: "apple puree - carbohydrate". Apple puree was received from the apples "Antonovka", (Kiev region, Ukraine) and had the following physical-chemical parameters: content of dry substances $-10 \%$, saccharose $-1,3 \%$, reducing substances $-7,5 \%$, acidity (in recalculation on apple acid $-0,8 \%$ ), pectin content $-0,9 \%$.

As carbohudrates were used: saccharose with content of dry substances - 99,85\%; glucose - with content of dry substances $91 \%$; fructose - with content of dry substances $98 \%$, lactulose with content of dry substances $99,9 \%$.

For the formation of studied receipt compositions of confectionary products of gel structure there was accepted the apple puree and carbohydrate ratio 1,3:1,0. Such ratio is most often used in the receipts of confectionary products [7]. The quantity of carbohydrates (saccharose, glucose, fructose) was calculated according to the equal quantity of dry substances. The studied models were presented as following:

$-130 \mathrm{~g}$ of apple puree (10\% of dry substances) $+100 \mathrm{~g}$ of saccharose $(99,85 \mathrm{~g}$ of dry substances);

- $130 \mathrm{~g}$ of apple puree $+109,72 \mathrm{~g}$ of glucose $(99,85 \mathrm{~g}$ of dry substances);

$-130 \mathrm{~g}$ of apple puree $+101,89 \mathrm{~g}$ of fructose $(99,85 \mathrm{~g}$ of dry substances).

The moisture of three models was respectively 51,0; 52,93; 51,34\%. All three models underwent boiling to $70 \%$ of dry substances that corresponded to the moisture $30 \%$. The boiled masses, corresponded to the sol state, were cooled to the temperature $293 \mathrm{~K}\left(20^{\circ} \mathrm{C}\right)$ and were kept during 120 minutes for formation of pectin gel structure. The given temperatures and time parameters correspond to the technological modes of formation of structure of fruit-berry jelly candy and filings in technological systems of manufacturing jelly candy and products with filling $[1,2,8]$. The structural-mechanical characteristics were determined in the formed gel systems.

At manufacturing of pectin gels with lactulose its quantity must provide the day norm of lactulose for human organism that is $3 \ldots 10 \mathrm{~g}$ [15]. Hence, in receipts of gels, based of saccharose, glucose and fructose $10 \%$ of sugar were replaced with lactulose that corresponded to the maximal value of lactulose norm, recommended for healthy human. For prevention of possible hydrolysis lactulose was brought in the composition of prescribed mixture at the end of boiling, at temperature $378-383 \mathrm{~K}\left(105 \ldots 110^{\circ} \mathrm{C}\right)$, when the system was in sol state yet that allowed the full solution of lactulose. The temperature decrease would lead to the gel formation.

Rheological properties were studied using rotary viscosimeter Rheotest-2.1 («Mettingen» firm, Germany, 1981) [16]. The calculations of rheological parameters were carried out according to the method [17]: $\eta_{\mathrm{ef}}^{0}$ - effective viscosity of non-destructed gels structure; $\eta_{\mathrm{ef}}^{\mathrm{b}}$ - effective viscosity of destructed structure; $\eta_{\mathrm{ef}}^{\mathrm{r}}$ - effective viscosity of restored structure.

The solidity of pectin gel was determined according to improved methodology on apparatus Valenta VC (CJSC "SPE Foodprodautomatics", Ukraine) [18], based on the principle of the measurement of force, affecting the form with gel.

The study of the free and bound moisture quantity in the model solutions of polysaccharides was carried out using derivatograph Q-1500 (MOM firm, Paulik-Paulik-Erdey system (Hungry)). In the test sample were synchronously measured the temperature (curve T), mass change (curve TG), speed of mass change (curve DTG) and change of thermal capacity (curve DTA) depending on time: Fig. 1.

According to derivatogramms the value of mass loss $(\Delta \mathrm{m})$ of studied sample at correspondent temperature was determined and the quantity of free and bound moisture was calculated [19]. At analysis it was conventionally accepted, that the moisture, extracted from the sample before the boiling temperature can be considered as free and the one that is extracted from the sample after the boiling temperature - as bound. As soon as the boiling temperature for the solutions of different sugars essentially differs and depends on their concentration, it was calculated, that boiling tem- 
peratures of the samples of studied pectin gels must correspond to the $80 \%$ sugars solution. Thus, the pectin gels with moisture $30 \%$ that at heating up to $373 \mathrm{~K}\left(100{ }^{\circ} \mathrm{C}\right)$ lost $\approx 10 \%$ of moisture, and which content of dry substances increased up to $80 \%$ to this moment, were used in the research. Taking into account the data [20], the boiling temperature of $80 \%$ solutions of saccharose, glucose, fructose is $382,1 \mathrm{~K}\left(109,4{ }^{\circ} \mathrm{C}\right), 386 \mathrm{~K}\left(113{ }^{\circ} \mathrm{C}\right)$ and $397 \mathrm{~K}\left(124{ }^{\circ} \mathrm{C}\right)$ respectively. That is why the moisture on TG curve was considered as free up to the moment of attainment the temperature $382,1 \mathrm{~K}\left(109,4^{\circ} \mathrm{C}\right)$ by gel-sol on sacharose; $386 \mathrm{~K}\left(113{ }^{\circ} \mathrm{C}\right)$ - by gel-sol on glucose; $397 \mathrm{~K}\left(124{ }^{\circ} \mathrm{C}\right)-$ by gel-sol on fructose.

The assessment of the results of experimental studies was carried out using the methods of calculation of statistical reliability of measured results. Approximation of empirical data was carried out using e-tables MSExcel.

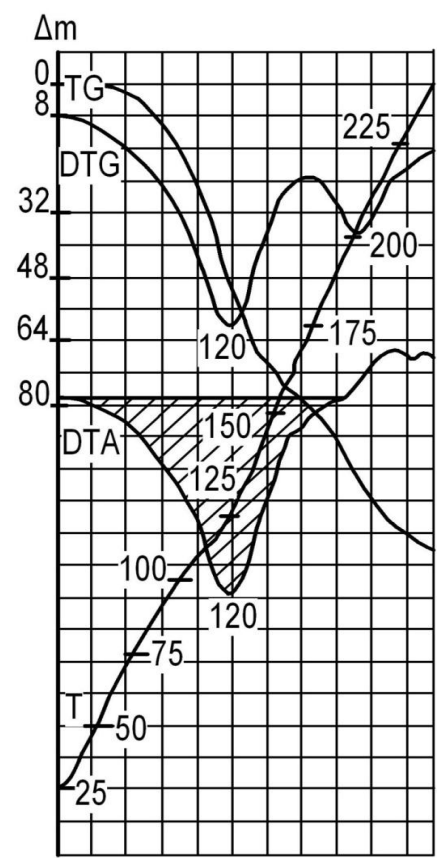

Fig. 1. Derivatogramm of pectin gel on the base of apple puree and fructose

\section{1. Experimental procedures}

Rheological characteristics of pectin gels in diapason from 2,45 to $1073 \mathrm{~s}^{-1}$ (destruction of structure to the sol state) and in diapason from 1073,00 to 2,45 s-1 (restoration of structure to the gel state) are presented in the Table $\mathbf{1}$.

Table 1

Rheological characteristics of pectin gels

\begin{tabular}{cccc}
\hline Pectin gel on & $\boldsymbol{\eta}_{\mathrm{ef}}{ }^{0}, \mathbf{P a} \cdot \mathbf{s}$ & $\boldsymbol{\eta}_{\mathrm{ef}}{ }^{\mathrm{b}}, \mathbf{P a} \cdot \mathbf{s}$ & $\boldsymbol{\eta}_{\mathrm{ef}}{ }^{\mathrm{r}}, \mathbf{P a} \cdot \mathbf{s}$ \\
\hline saccharose & $47,1 \pm 1,5$ & $0,9 \pm 0,1$ & $8,5 \pm 0,5$ \\
glucose & $62,5 \pm 1,5$ & $1,05 \pm 0,1$ & $13,5 \pm 0,5$ \\
fructose & $61,3 \pm 1,5$ & $1,1 \pm 0,1$ & $13,3 \pm 0,5$ \\
Gel on glucose with decrease of its quantity by $30 \%$ & $49,34 \pm 1,5$ & $1,09 \pm 0,1$ & $12,67 \pm 0,5$ \\
Apple puree, saccharose, lactulose & 40,3 & 8,5 & 7,1 \\
Apple puree, fructose, lactulose & 63,9 & 8,2 & 29,0 \\
Apple puree, glucose, lactulose & 44,2 & 1,1 & 11,3
\end{tabular}


The transformation of pectin sol into gel is attended with compression of structure. The results of the study of structure solidity of pectin gel on saccharose, glucose and fructose in the process of keeping are presented in the Table 2.

Table 2

Study of pectin gels solidity in the process of keeping

\begin{tabular}{cccccc}
\hline \multirow{2}{*}{ Pectin gel } & \multicolumn{5}{c}{ Pectin gel solidity at temperature $\mathbf{2 9 3} \mathbf{K}\left(\mathbf{2 0}{ }^{\circ} \mathbf{C}\right), \mathbf{g}$} \\
& $\mathbf{2}$ hours & $\mathbf{6}$ hours & $\mathbf{1 0}$ hours & $\mathbf{2 4}$ hours & $\mathbf{3 6}$ hours \\
\hline saccharose & 322,0 & 350,2 & 385,4 & 396,8 & 405,6 \\
fructose & 393,7 & 443,1 & 474,1 & 480,5 & 482,5 \\
glucose & 483,5 & 523,9 & 576,3 & 584,5 & 599,3
\end{tabular}

The analysis of results of differential thermal analysis of gel systems with sugars is presented in the Table 3.

Table 3

The content of free and bound moisture of pectin gels on saccharose, glucose, fructose, lactulose

\begin{tabular}{cccc}
\hline Pectin gel on the base & $\begin{array}{c}\text { Total quantity of moisture, } \\
\text { extracted from } \\
\text { the sample at heating, \% }\end{array}$ & $\begin{array}{c}\text { Moisture content, } \\
\text { \% of the total quantity } \\
\text { Free }\end{array}$ & 44,00 \\
Bound \\
\hline Apple puree, saccharose & 31,80 & 56,00 \\
Apple puree, saccharose, lactulose & 34,00 & 45,40 & 54,60 \\
Apple puree, glucose (with decrease of quantity by 30 \%) & 20,80 & 42,00 & 58,00 \\
Apple puree, glucose & 26,10 & 44,00 & 56,00 \\
Apple puree, fructose & & 58,00 & 42,00 \\
Apple puree, fructose, lactulose & 40,40 & 56,60 & 43,40
\end{tabular}

\section{Results}

The results of analysis of the data of Table 1 demonstrate that viscosity of pectin gel, based on glucose and fructose is 1,3 times more than the one of pectin gel, based on saccharose. The role of saccharose, glucose, fructose is both in the lowering of solvation of the structural pectin framework that favors coalescence of separate particles on desolvated zones and in appearance of hydrogenous connections between sugar molecules and dehydrated pectin molecules. Saccharose, glucose, fructose were brought in composition of pectin gel in quantities of equal dry substances mass. As soon as molecular mass of saccharose -342 , glucose and fructose -180 , the number of molecules of glucose and fructose is 1,9 more than saccharose molecules. That is more hydrogenous connections between sugars and pectin molecules are created in pectin gels, based on fructose and glucose. It favors the strengthening of structure of pectin gels on fructose and glucose.

The structure of all samples is strengthened with time: Table 2. In 10 hours of keeping in the sample on glucose was observed crystallization that was intensified with time. The cause of glucose crystallization is its low solubility: at temperature $293 \mathrm{~K}\left(20^{\circ} \mathrm{C}\right)$ glucose solubility is by $40 \%$ less than saccharose one and by $70 \%$ less that fructose one [20]. For prevention of glucose crystallization it was offered to lower its quantity. It was experimentally established, that the decrease of glucose in receipt by $30 \%$ simultaneously provides the homogenous structure of sample without crystallization and approximates the values of effective viscosity of non-destructed structure to the sample on saccharose, acted as the control sample. It would allow use the analogous technological modes of the fruit-berry mass formation without correction of production process. But at decrease of glucose its ratio with apple puree naturally changes, from 1,3:1 to 1,7:1,0, that is necessary to be taken into account at elaboration of receipts of the new types of confectionary products. 
At the use of lactulose in composition of pectin gel, based on saccharose, its effective viscosity of non-destructed structure decreases by $14,5 \%$; for gel with glucose - by $10,4 \%$, and for gel with fructose, on the contrary, the viscosity increase by $4,2 \%$ was observed. Such influence of lactulose is explained by the differences in solubility of the studied sugars. Thus, at $293 \mathrm{~K}\left(20^{\circ} \mathrm{C}\right)$ lactulose solubility is $75,2 \%$, that is by $12 \%$ more than saccharose solubility, by $57 \%$ more than glucose solubility and by $4 \%$ less than fructose solubility [20].

It was established, that the replacement of $10 \%$ of saccharose or glucose by lactulose favors the increase of free water and naturally increases the total number of water, eliminated at heating. It is explained by the increase of total solubility of sugars in the system "pectin-saccharose-lactulose" and "pectin-glucose-lactulose" comparing with monocomponent solutions of saccharose and glucose. For gels, based on fructose, the addition of lactulose, on the contrary, increases the quantity of bound water, in which connection such systems give away less moisture at heating. It is connected with the decrease of solubility parameter of sugars in fructose-lactulose combination, comparing with gels, based on fructose.

\section{Conclusions}

The studies of rheological properties of pectin gels with mono- and disaccharides allowed form the generalazied scientific information about the structure of pectin gels on the base of apple puree and saccharose, glucose, fructose, lactulose. The established data ground the technological modes of gel-like confectionary masses formation. Thus, the more parameters of effective viscosity of gels, based on glucose and fructose, comparing with gels, based on saccharose, testify to the fact that under production conditions the temperature of formation of such masses must be increased. And the decrease of effective viscosity of gels at addition of lactulose, on the contrary, widens the temperature interval of masses formation because they can be formed at lower temperatures.

The data about change of quantitative ratio of apple puree and sugars must be taken into account at elaboration of receipts of fruit candy, fruit jelly, filling for caramel, cookies, muffins, biscuits, cakes, spice-cakes and pies for child, deictic, functional food.

Thus, the presented researches continue and develop scientific notions about regularities of gels formation by pectin substances of fruit-berry raw material. They are the base for the study of elastic-plastic, sorption and other gels properties that are developed at storage.

\section{References}

[1] Buteykis, N. G., Zhukova, A. A. (2000). The Technology of making flour confectionery. Moscow: Academy, 302.

[2] Dragilev, A. I. (2003). Production of chocolates and toffee: a training manual. Moscow: JSC «Textbooks», 368.

[3] Oleinikov, A. I., Magomedov, G. O., Miroshnikova, T. N. (2005). Workshop on technology of confectionery. Saint Peterburg: GIORD, 480.

[4] Zubchenko, A. V. (2001). Physico-Chemical Bases confectionary technology of products. Voronezh State-owned technological academy, 389.

[5] Yoo, B., Yoo, D., Kim, Y.-R. (2003). Effects of sugar type on rheological properties of high methoxyl pectin gel. Food Science and Biotechnology, 12 (3), 316-319.

[6] Donchenko, L. V., Firsov, G. G. (2007). Pectin: basic properties, production and application. Moscow: Delhi Print, 276.

[7] Pavlov, N. S. (2000). A collection of basic recipes sugar confectionery. Saint Peterburg: GIORD, 232.

[8] Manley, D. (2012). Flour confectionery with recipes. Profession, 720.

[9] Grosso, C. R., Bobbio, P., Airoldi, C. (2000). Effect of sugar and sorbitol on the formation of low methoxyl pectin gels. Carbohydrate Polymers, 41 (4), 421-424. doi: 10.1016/s0144-8617(99)00099-5 
[10] Lobosova, L. A. (2007). Development of technology for Zephyr functional purpose on the basis of fructose. Voronezh state technological Academy, 19.

[11] Avetisyan, K. V. (2015). Improvement of technology, double-layered jelly marmalade with the use of starch syrups. Odessa national Academy of food technologies, 23.

[12] Krats, R., Kolesnikov, A. Y. (1997). New jelly marmalade on pectin. Food industry, 2, 20-21.

[13] Magomedov, G. A., Magomedov, A. K., Miroshnikova, T. N., Lobosova L. A. (2007). The effect of fructose on studiobuhne in the production of marshmallows. Confectionery production, 2, 31-33.

[14] Solovyova, O. L. (2011). Improvement of the technology of jelly marmalade special consumption. Kyiv: National University of food technologies, 20.

[15] Weber, F. L. (1997). Effects of Lactulose on Nitrogen Metabolism. Scandinavian Journal of Gastroenterology, 32 (sup222), 83-87. doi: 10.1080/00365521.1997.11720726

[16] Grabovsky, O. V., Kowalewska, Ye. I. (2009). Rheology of food products: methodical instructions to performance laboratory work's for students specialty "Technology of bread, confectionery, pasta and food concentratess" directly "Food technology and engineering" full-time education. Kyiv: National University of food technologies, 22.

[17] Goralczyk, A. B., Pivovarov, P. P., Grinchenko, O. A. et. al. (2006). Rheological methods of research of raw materials and food products and automation of calculations of rheological characteristics: a training manual. Kharkiv state University of food technology and trade, 63.

[18] Lurie, I. S., Skokan, L. E., Tsitovich, A. P. (2003). Technical and microbiological control in the confectionery industry. Moscow: Kolos, 415.

[19] Pimenova, L. N. (2005). Thermography. Methodical instructions for laboratory work on discipline "Physical and chemical methods of research". Tomsk University of architecture and construction, 19.

[20] Zhuravleva, E. (Ed.). (1966). The reference to the Baker. P.1. Raw materials and technology for confectionery production. Moscow: Foodindustry, 712. 